\title{
Estimated length of stay calculated by "diagnosis- related groups" in patients with prostate cancer: a retrospective analysis
}

Daniel Melecchi Freitas', Isabelle W Zorzo', Gisele Bastos Nader¹, Eduardo Franco Carvalhal', Jussara Maccari' ${ }^{1}$, Luiz Nasi ${ }^{1}$, Mauro Weiss ${ }^{1}$

\begin{abstract}
Introduction: To evaluate whether the presence of bone metastasis in hospitalized patients with prostate cancer (PCa) is associated with a longer length of stay (LOS) when compared to LOS estimated by diagnosis-related groups (DRG). Methods: We performed a retrospective analysis of 86 admissions of patients with PCa at our facility in 2018-2019. Admissions were divided into two groups based on actual LOS and LOS estimated by DRG: group 1 (actual LOS $\geq$ DRG-LOS) and group 2 (actual LOS<DRG-LOS). The association of bone metastasis and other variables with increased LOS was evaluated by logistic regression with univariable and multivariable analysis, controlling baseline patient characteristics. Results: Longer LOS was not associated with baseline characteristics (age, body mass index, and presence of comorbidities), but was significantly associated with type of admission and ICU (intensive care unit) admission during hospitalization ( $p<0.05)$. Bone metastasis was observed in $28(68.3 \%)$ of group 2 admissions and was independently associated with increased LOS (group 2) on univariable and multivariable analysis ( $\mathrm{OR}=4.76,95 \% \mathrm{Cl}=1.91-11.8, \mathrm{p}=0.001$; $\mathrm{OR}=3.48,95 \% \mathrm{Cl}=1.08-11.2, \mathrm{p}=0.03$, respectively). Conclusion: Among clinical or surgical admissions of patients with PCa over a 1-year period, presence of bone metastasis was independently associated with increased LOS when compared to LOS estimated by DRG. The presence of bone metastasis may be used to identify possible outliers not recognized by the DRG system.
\end{abstract}

Keywords: Prostatic neoplasm; Diagnostic-related groups; Bone metastasis; Length of stay. 


\section{RESUMO}

Introdução: Avaliar se a presença de metástases ósseas em pacientes hospitalizados com câncer de próstata (CaP) está associada a um maior tempo de internação (TI) quando comparado ao LOS estimado por grupos de diagnóstico relacionados (GDRs). Métodos: Realizamos uma análise retrospectiva de 86 admissões de pacientes com CaP em nosso serviço em 20182019. As admissões foram divididas em dois grupos com base no TI real e no TI estimado pelo GDR: grupo 1 (TI real $\geq G D R-T I$ ) e grupo 2 (TI real<GDR-TI). A associação de metástases ósseas e outras variáveis com TI aumentada foi avaliada por regressão logística com análise univariável e multivariável, controlando as características basais do paciente. Resultados: O tempo de permanência prolongado não foi associado às características basais (idade, índice de massa corporal e presença de comorbidades), mas foi significativamente associado ao tipo de admissão e à admissão na UTI (unidade de terapia intensiva) durante a internação $(p<0.05)$. Metástase óssea foi observada em 28 (68,3\%) das admissões do grupo 2 e foi independentemente associada com aumento do TI (grupo 2) na análise univariável e multivariável (OR=4,76, IC $95 \%=1,91-11,8, p=0,001 ; O R=3,48, I C \quad 95 \%=1,08-11,2, p=0,03$, respectivamente). Conclusão: Entre as internações clínicas ou cirúrgicas de pacientes com CaP ao longo de um período de 1 ano, a presença de metástases ósseas foi independentemente associada ao aumento do Tl em comparação com o TI estimado pelo GDR. A presença de metástases ósseas pode ser usada para identificar possíveis outliers não reconhecidos pelo sistema GDR.

Descritores: Neoplasia prostática; Grupos de diagnósticos relacionados; Metástase óssea; Tempo de permanência.

\section{INTRODUCTION}

Diagnosis-related group (DRG) is a classification based on patient diagnosis and illness severity that is used as a care performance indicator and to analyze hospital costs. (1) In the United States, it has been used as a system of prospective payment for Medicare reimbursement since the 1980's.(2) Moreover, as new technologies and treatments have been developed, the DRGs have been updated, with several new editions published over the years. ${ }^{(3)}$ In Brazil, however, the DRG system has only been implemented in the last 10 years, which is consistent with the epidemiological reality of the country.

Prostate cancer (PCa) is one of the most common malignancies in men worldwide.(4) Tumor stage and patient performance status dictate the treatment strategy, which may vary from surgery and radiotherapy with curative intent to chemotherapy and androgen-deprivation therapy (ADT) for disease control in the metastatic setting. ${ }^{(5)}$ Several promising options have emerged for later-line treatment of recurrent or metastatic PCa. Recent clinical trials with abiraterone and enzalutamide have demonstrated benefits regarding overall survival, while apalutamide also showed increased metastasis free-survival in castration-resistant PCa (CRPCa). ${ }^{(6-9)}$ However, new treatments and longer survival have been associated with increased costs, especially in patients with metastatic cancer. One recent study estimated that health costs have been increasing by almost US $\$ 9,000$ per month per patient when using new lines of treatment. ${ }^{(10)}$ Additionally, patients with PCa diagnosed with bone metastasis now have a mean overall survival of 7.5 years. ${ }^{(11)}$

Although several parameters have a higher impact on case-mix weight and are associated with increased hospital costs, length of stay (LOS) is among the most important variables of interest during hospitalization that are used by the DRG system. Increased LOS may be caused by disease-related factors or hospital-related circumstances, such as access to healthcare or even the day of the week a patient is admitted. ${ }^{(8)}$ For example, Panagiotopoulos et al. (ANO)(x) analyzed oncologic DRGs in an internal medicine department and found that LOS was the main factor for hospital under-reimbursement. Furthermore, inpatient facility costs are the largest component of medical resource utilization in patients with metastatic $\mathrm{PCa}$, demonstrating that disease progression is directly associated to a higher economic impact. ${ }^{(12)}$

It is well established that patients with PCa with or without metastasis demand an increased amount of financial resources, mainly because of new treatment technologies, prescription of novel drugs, or the presence of skeletal-related events. ${ }^{(13)}$ However, it is not completely understood whether the DRG system is able to predict and explain the differences in LOS in case-mix groups. ${ }^{(14)}$ To date, there are no data comparing length of hospitalization for any cause in patients with $\mathrm{PCa}$, with or without metastasis, adjusted by confounders. Therefore, we sought to compare whether hospital admissions of patients diagnosed with PCa and bone metastasis are associated with increased LOS when compared to DRG- estimated, in 
a population of patients receiving regular outpatient care who required hospital admission for any cause.

\section{MATERIAL AND METHODS}

\section{Study sample}

We reviewed data from medical records of subjects previously diagnosed with PCa who were admitted to Hospital Moinhos de Vento, Porto Alegre, Brazil. The eligibility criteria were diagnosis of any stage $\mathrm{PC}$, regular care at the outpatient clinic at the time of data collection, and hospitalization for any cause during the years 2018 and 2019. All patients were DRG-scored using the Brazilian DRG system that is coded by major diagnostic categories, clinical or surgical admission and comorbidities, and generates an estimate LOS.(1) Patients coming from outside facilities were excluded. A total of 86 hospitalizations were included, and no patient was excluded during analysis. Hospitalization longer than estimated by DRG (>DRG-LOS) was described as a LOS of at least 1 day longer than that estimated by the system.

\section{Statistical analysis}

The objective of the study was to evaluate the association among LOS, LOS estimated by DRG, and presence of bone metastasis in patients with PCa. Patients were divided into 2 groups: LOS $\leq$ DRG-LOS (actual LOS shorter than or equal to that estimated by DRG, group 1); or LOS>DRG-LOS (actual LOS Ionger than that estimated by DRG, group 2). Comparisons of baseline characteristics between groups 1 and 2 were performed using chi-squared test for categorical variables and Student's t-test for continuous variables baseline characteristics evaluated were: age (continuous in years), body mass index (BMI, continuous in $\mathrm{kg} / \mathrm{m} 2$ ), type of admission (dichotomous, clinical or surgical), presence of comorbidities (dichotomous, $>2$ or $\leq 2$ comorbidities), intensive care unit (ICU) admission during hospitalization (dichotomous, yes or no) and bone metastasis (dichotomous, yes or no). The association of group 2 and presence of metastasis was evaluated using logistic regression in univariable and multivariable analyses, controlling for baseline covariates (age, BMI, type of admission, ICU admission, and presence of comorbidities). Statistical analyses were performed using SPSS version $21 ; p<0.05$ was considered to indicate statistical significance.

\section{RESULTS}

A total of 86 hospital admissions were studied. Mean age was $76.6( \pm 9.4)$ years, and mean BMI was 25.9 $( \pm 5.8) \mathrm{kg} / \mathrm{m}^{2}$ (Table 1). Among all medical hospitalizations, urology was the most commonly represented specialty, accounting for $31.4 \%$ (27 admissions), followed by clinical oncology with $30.2 \%$ (26 admissions) (Supplementary Table 1). The most frequent ICD-10 on hospitalization was PCa $(\mathrm{N}=24)$; however, there were 50 different ICD-10 codes described at admission (Supplementary Table 2). Mean LOS was significantly higher in the overall sample when compared to estimated DRG-LOS (7.5 \pm 7.3 and $4.4 \pm 2.9, p=0.014)$
(Supplementary Table 3). Group 2 (LOS>DRGLOS) was significantly associated with admission for clinical treatment $(\mathrm{OR}=3.54,95 \% \mathrm{Cl}=1.40-8.91$, $p=0.007)$ and admission at ICU during hospitalization (OR=5.37, 95\% Cl=1.58-17.8, $p=0.007)$. (Table 2). The prevalence of bone metastasis in groups 1 and 2 was $31.1 \%$ and $68.3 \%$, respectively. Bone metastasis was positively associated with group 2 status (LOS>DRGLOS) on univariable and multivariable analysis $(\mathrm{OR}=4.76,95 \% \mathrm{Cl}=1.91-11.8, p=0.001$ and $\mathrm{OR}=3.48$, 95\% Cl=1.08-11.2, $p=0.03$, respectively) (Table 3 ). Others baseline characteristics were not significantly different between groups 1 and 2 . All patients were alive at discharge.

Table 1. Baseline characteristics.

$\begin{array}{lcc}\text { Variables } & \text { LOS } & \\ & \text { Group 1 } & \text { Group 2 } \\ \text { N (\%) } & 45(52.3) & 41(47.7) \\ \text { Age (years), mean } & 74.9 & 78.3(9.0) \\ \text { (SD) } & (9.6) & \\ \text { BMI (kg/m²), mean } & 25.9 & 25.8(6.1) \\ \text { (SD) } & (5.5) & \\ \text { Admission-DRG, N } & & \\ \text { (\%) } & & \\ \text { Clinical } & 21(46.7) & 31(75.6) \\ \text { Surgical } & 24(53.3) & 10(24.4) \\ \text { ICU admission, N } & & \\ \text { (\%) } & & \\ \text { Absent } & 41(69.3) & 27(39.7) \\ \text { Present } & 4(22.2) & 14(77.7) \\ \text { Comorbidities, N (\%) } & & \\ \leq 2 & 33(73.3) & 29(70.7) \\ \text { >2 } & 12(26.7) & 12(29.3) \\ \text { Bone metastasis, N } & & \\ \text { (\%) } & & \\ \text { Absent } & 31(68.9) & 13(31.7) \\ \text { Present } & 14(31.1) & 28(68.3)\end{array}$

BMI: Body mass index; SD: Standard deviation; DRG: Diagnosis-related groups; ICU: Intensive care unit.

Table 2. Association between baseline characteristics and group 2 (actual LOS>LOS estimated by DRG).

$\begin{array}{lccc}\text { Variable } & \text { OR } & 95 \% \mathrm{Cl} & p \\ \text { Age (years) } & 1.04 & 0.99-1.09 & 0.099 \\ \text { BMI (kg/m²) } & 0.99 & 0.92-1.07 & 0.920 \\ \begin{array}{l}\text { Admission-DRG } \\ \text { Surgical }\end{array} & \text { ref. } & -- & -- \\ \text { Clinical } & 3.54 & 1.40-8.91 & 0.007 \\ \text { Comorbidities } & & & \\ \leq 2 & \text { ref. } & -- & -- \\ >2 & 0.87 & 0.34-2.25 & 0.788 \\ \text { ICU admission } & & & \\ \text { Absent } & \text { ref. } & -- & -- \\ \text { Present } & 5.37 & 1.58-17.8 & 0.007\end{array}$

BMI: Body-mass index; Cl: Confidence interval; OR: Odds ratio; IUC: Intensive unit care; ref.: Reference. 
Table 3. Association between LOS and presence of metastasis.

\begin{tabular}{lcccccccc}
\hline \multirow{2}{*}{ LOS } & \multicolumn{2}{c}{ Bone metastasis } & \multicolumn{3}{c}{ Univariable } & \multicolumn{3}{c}{ Multivariable } \\
Group 1 & Absent & Present & OR & $95 \% \mathrm{Cl}$ & $p$ & OR & $95 \% \mathrm{Cl}$ & $p$ \\
\cline { 2 - 9 } Group 2 & $13(31.7)$ & $28(68.3)$ & 4.76 & $1.91-11.8$ & 0.001 & 3.48 & $1.08-11.2$ & 0.03 \\
\hline
\end{tabular}

LOS: Length of stay; Cl: Confidence interval; OR: Odds ratio; ref.: Reference.

\section{DISCUSSION}

DRGs are one of the most important tools to analyze optimal allocation of medical resources in healthcare systems. ${ }^{(1)}$ First utilized in the U.S. in the 1980s, DRG coding started to be used in healthcare systems in several other countries in the last decades.(15) DRGs are formulated based on the diagnosis (divided into major diagnostic categories), type of admission (clinical or surgical), and comorbidities, which generate codes and estimate LOS for each case..$^{(1,16)}$ More recently, this system has been used to support quality improvements and the achievement of higher efficiency in healthcare.

PCa has an important impact on financial resources utilization due to its high prevalence and incidence. Worldwide, more than 1.3 million patients were diagnosed with PCa in 2018 alone. ${ }^{(4)}$ In addition, major advances in treatments with curative intent and new medications to manage disease recurrence or control metastasis have not only improved overall survival and quality of life, but also increased costs. ${ }^{(11)}$ However, whether the presence of recurrent PCa or metastatic disease has any impact on the homogeneity of DRG system categorization is still a matter of debate. Therefore, we sought to evaluate whether patients with PCa and bone metastasis had a longer actual LOS when compared to estimated DRG-LOS on admission when hospitalized due to any cause. We found that admissions of patients with PCa and bone metastases were significantly associated with increased duration of hospitalization when compared to the estimated DRG-LOS.

LOS is an important metric to evaluate costs in healthcare. ${ }^{(17)}$ Additionally, some studies have demonstrated that LOS may be associated with increased costs of clinical and surgical hospitalizations. ${ }^{(8,18,19)}$ For instance, Fine et al. (2000), ${ }^{(18)}$ in a multicenter study analyzing patients admitted with community-acquired pneumonia, revealed considerable cost savings with as little as a 1-day reduction in LOS. Moreover, a recent review of 37 studies indicated that enhanced recovery programs versus conventional management decreased the LOS after abdominal surgeries and were substantially associated with cost savings. ${ }^{(19)}$ It seems that duration of hospitalization is directly correlated with consumption of health resources.

Although the majority of patients at the time of PCa diagnosis have localized disease, almost 30\% will develop bone metastasis during follow-up. ${ }^{(20)}$ In our study, among all admissions, PCa with bone metastasis was present in 42 (48.8\%) and was independently associated with increased LOS. As long as patients with metastatic PCa have access to adequate treatment (androgen deprivation therapy), long overall survival and even increased metastasis free-survival can be expect- ed for this group. Data from CaPSURE, which analyzed more than 12,000 patients from 1990 to 2004, found that PCa-specific survival at 5 years was $71 \%(95 \%$ $\mathrm{Cl}=62-78)$. $^{(11)}$ A recent double-blind clinical trial that studied the androgen receptor inhibitor apalutamide in non-metastatic castration-resistant PCa found a significant survival free of metastasis when compared to placebo (HR 0.28; 95\% Cl=0.23-0.35). ${ }^{(21)}$ Thus, given the fact that, in our study, PCa with bone metastasis was associated with a 3.48-fold increase in risk for longer LOS even after adjusting for other variables, it is plausible to think that new medications that prevent development of bone metastases may also lead to shorter LOS when these patients are hospitalized.

Analysis of patient characteristics that may increase or decrease LOS is of interest for hospital reimbursements and performance analysis. Some studies have evaluated factors that may influence these scenarios. $(12,16)$ For example, in a large study that evaluated the duration of hospitalization of patients with acute coronary syndromes, the authors found that diabetes and cerebrovascular disease were directly associated with increased LOS, with a higher weight when compared to other comorbidities, and concluded that the presence of this two diseases should be linked to higher reimbursement.(22) In another study, Freitas et al. (2012), (23) analyzed variables associated with LOS outliers in the Portuguese National Health Service and found that addition of each comorbidity in the statistical model resulted in an adjusted OR of 1.41. In our analysis, comorbidities were not correlated with actual LOS higher than estimated DRG-LOS. However, as we did not analyze specific types of comorbidities, further studies are necessary to assess the real impact of specific medical conditions during hospitalization in PCa patients.

Our study has some limitations. First, our data were collected from a single private hospital. Second, we selected only patients who were receiving regular outpatient follow-up at our clinic, to ensure data quality. Notably, the majority of patients who were hospitalized at our institution came from outside facilities, which restricted the number of admissions in our sample. Third, DRG coding and data were collected retrospectively. Finally, we did not study types of comorbidities or severity of bone disease, as indicated by pain or number of metastases.

\section{CONCLUSION}

To the best of our knowledge, this was the first study to analyze the association between LOS estimated by DRG and PCa. We found that, among admissions of patients diagnosed with PCa, the presence of bone metastasis was independently associated with significantly longer actual LOS when compared with LOS estimated by 
DRG. This finding has implications for hospital resources allocation and efficiency analysis. The advent of new medications that increase metastasis-free survival in patients diagnosed with recurrent non-metastatic PCa may decrease LOS when these patients are hospitalized. The presence of bone metastases may be used to identify possible outliers who are not recognized by the DRG system.

\section{REFERENCES}

1. Simborg DW. DRG creep: a new hospital-acquired disease. N Engl J Med. 1981 Jun;304(26):1602-4.

2. Garber AM, Fuchs VR, Silverman JF. Case mix, costs, and outcomes. Differences between faculty and community services in a university hospital. N EnglJ Med. 1984 May;310(19):1231-7.

3. Martins M, Travassos C, Carvalho de Noronha J. Hospital information systems as risk adjustment in performance indicators. Rev Saude Publica. 2001 Apr;35(2):185-92.

4. Bray F, Ferlay J, Soerjomataram I, Siegel RL, Torre LA, Jemal A. Global cancer statistics 2018: GLOBOCAN estimates of incidence and mortality worldwide for 36 cancers in 185 countries. CA Cancer J Clin. 2018 Nov;68(6):394-424.

5. Sathianathen NJ, Konety BR, Crook J, Saad F, Lawrentschuk N. Landmarks in prostate cancer. Nat Rev Urol. 2018 Oct;15(10):627-42.

6. Ryan CJ, Smith MR, Bono JS, Molina A, Logothetis CJ, Souza $\mathrm{P}$, et al. Abiraterone in metastatic prostate cancer without previous chemotherapy. N Engl J Med. 2013 Jan;368(2):138-48.

7. Shore ND, Chowdhury S, Villers A, Klotz L, Siemens DR, Phung $D$, et al. Efficacy and safety of enzalutamide versus bicalutamide for patients with metastatic prostate cancer (TERRAIN): a randomised, double-blind, phase 2 study. Lancet Oncol. 2016 Feb;17(2):153-63.

8. Schmidt WP, Taeger D, Buecker-Nott HJ, Berger K. The impact of the day of the week and month of admission on the length of hospital stay in stroke patients. Cerebrovasc Dis. 2003 Feb; 16(3):247-52.

9. Chi KN, Agarwal N, Bjartell A, Chung BH, Gomes AJPS, Given $\mathrm{R}$, et al. Apalutamide for metastatic, castration-sensitive prostate cancer. N Engl J Med. 2019 Jul;381(1):13-24.

10. Wen L, Yao J, Valderrama A. Evaluation of treatment patterns and costs in patients with prostate cancer and bone metastases. J Manag Care Spec Pharm. 2019 Mar;25(3B Suppl):S1-S11.
11. Ryan CJ, Elkin EP, Cowan J, Carroll PR. Initial treatment patterns and outcome of contemporary prostate cancer patients with bone metastases at initial presentation: data from CaPSURE. Cancer. 2007 Jul; 110(1):81-6.

12. Li TT, Shore ND, Mehra M, Todd MB, Saadi R, Leblay G, et al. Impact of subsequent metastases on costs and medica resource use for prostate cancer patients initially diagnosed with localized disease. Cancer. 2017 Sep;123(18):3591-601.

13. Roghmann F, Antczak C, McKay RR, Choueiri T, Hu JC, Kibel AS, et al. The burden of skeletal-related events in patients with prostate cancer and bone metastasis. Urol Oncol. 2015 Jan;33(1):17.e9-17.e18.

14. DesHarnais SI, Forthman MT, Homa-Lowry JM, Wooster LD Risk-adjusted clinical quality indicators: indices for measuring and monitoring rates of mortality, complications, and readmissions. Qual Manag Health Care. 2000;9(1):14-22.

15. Noronha MF, Veras CT, Leite IC, Martins MS, Braga Neto $\mathrm{F}$, Silver L. The development of diagnosis-related groups-DRG's. Methodology for classifying hospital patients. Rev Saude Publica. 1991 Jun;25(3):198-208

16. Souza J, Santos JV, Canedo VB, Betanzos A, Alves D, Freitas A. Importance of coding co-morbidities for APR-DRG assignment: focus on cardiovascular and respiratory diseases. Health Inf Manag. 2020 Jan;49(1):47-57.

17. Schwartz WB, Mendelson DN. Hospital cost containment in the 1980s. Hard lessons learned and prospects for the 1990s. N Engl J Med. 1991 Apr;324(15):1037-42.

18. Fine MJ, Pratt HM, Obrosky DS, Lave JR, McIntosh LJ, Sing er DE, et al. Relation between length of hospital stay and costs of care for patients with community-acquired pneumonia. Am J Med. 2000 Oct;109(5):378-85.

19. Joliat GR, Hubner M, Roulin D, Demartines N. Cost analysis of enhanced recovery programs in colorectal, pancreatic, and hepatic surgery: a systematic review. World J Surg. 2020 Mar:44(3):647-55.

20. Lu-Yao GL, Albertsen PC, Moore DF, Shih W, Lin Y, DiPaola $\mathrm{RS}$, et al. Outcomes of localized prostate cancer following conservative management. JAMA. 2009 Sep;302(11):1202-9.

21. Smith MR, Saad F, ChowdhuryS, Oudard S, Hadaschik BA, Graff JN, et al. Apalutamide treatment and metastasis-free survival in prostate cancer. N Engl J Med. 2018 Apr;378(15):1408-18.

22. Bramkamp M, Radovanovic D, Erne P, Szucs TD. Determinants of costs and the length of stay in acute coronary syndromes: a real life analysis of more than 10,000 patients. Cardiovasc Drugs Ther. 2007 Oct;21(5):389-98.

23. Freitas A, Silva-Costa T, Lopes F, Garcia-Lema I, Teixeira-Pinto $A$, Brazdil $P$, et al. Factors influencing hospital high length of stay outliers. BMC Health Serv Res. 2012 Aug;12:265.

$\begin{array}{lc}\text { Supplementary Table 1. Admissions by medical specialty. } \\ \text { Medical specialty } & \mathrm{N}(\%) \\ \text { Oncology } & 26(30.2) \\ \text { Cardiology } & 7(8.1) \\ \text { General surgery } & 2(2.3) \\ \text { Thoracic surgery } & 1(1.2) \\ \text { Vascular surgery } & 2(2.3) \\ \text { Internal medicine } & 12(14.0) \\ \text { Proctology } & 1(1.2) \\ \text { Gastroenterology } & 1(1.2) \\ \text { Infectious diseases } & 2(2.3) \\ \text { Nephrology } & 3(3.5) \\ \text { Neurosurgery } & 1(1.2) \\ \text { Neurology } & 1(1.2) \\ \text { Urology } & 27(31.4) \\ \text { Total } & 86(100)\end{array}$

BMI: Body-mass index; CI: Confidence interval; OR: Odds ratio; IUC: Intensive unit care; ref.: Reference. 
Supplementary Table 2. International Classification of Diseases (ICD) to each patient admission.

\begin{tabular}{|c|c|c|c|c|}
\hline Description & & $\mathrm{N}(\%)$ & & \\
\hline Aortic aneur & & & $2(2.4)$ & \\
\hline Aneurysm o & lower limb & & $1(1.2)$ & \\
\hline Unstable an & & & $2(2.4)$ & \\
\hline Aortic steno & & & $1(1.2)$ & \\
\hline Pneumonia & & & $2(2.4)$ & \\
\hline Cystitis & & & $1(1.2)$ & \\
\hline Ureteral cal & & & $1(1.2)$ & \\
\hline Acute procti & & & $1(1.2)$ & \\
\hline Unspecified & ions of medical care & & $1(1.2)$ & \\
\hline Pleural effus & & & $1(1.2)$ & \\
\hline Disorientati & & & $1(1.2)$ & \\
\hline Pain in limb & & & $1(1.2)$ & \\
\hline Pulmonary & & & $2(2.4)$ & \\
\hline Urethral ste & & & $1(1.2)$ & \\
\hline Atrial fibrilla & & & $2(2.4)$ & \\
\hline Hematuria & & & $2(2.4)$ & \\
\hline Bilateral ing & & & $2(2.4)$ & \\
\hline Hypo-osmo & רyponatremia & & $1(1.2)$ & \\
\hline Phimosis & & & $1(1.2)$ & \\
\hline Hypotensior & & & $1(1.2)$ & \\
\hline Male erectil & ion & & $1(1.2)$ & \\
\hline Myocardial & & & $1(1.2)$ & \\
\hline Cerebral inf & & & $1(1.2)$ & \\
\hline Urinary trac & & & $1(1.2)$ & \\
\hline Congestive & & & $2(2.4)$ & \\
\hline Acute kidne & & & $2(2.4)$ & \\
\hline Malignant $n$ & f prostate & & $21(26.8)$ & \\
\hline Malignant $n$ & f rectum & & $1(1.2)$ & \\
\hline Malignant n & unspecified & & $1(1.2)$ & \\
\hline Malignant $n$ & f pancreas & & $1(1.2)$ & \\
\hline Malignant $n$ & f ureter & & $1(1.2)$ & \\
\hline Malignant $\mathrm{n}$ & f bladder & & $2(2.4)$ & \\
\hline Malignant $n$ & f stomach & & $1(2.4)$ & \\
\hline Malignant $n$ & f lung & & $2(2.4)$ & \\
\hline Secondary $r$ & neoplasm of bone marrow & & $4(4.8)$ & \\
\hline Joint disord & & & $1(1.2)$ & \\
\hline Pathologica & & & $2(2.4)$ & \\
\hline Unspecified & struction & & $1(1.2)$ & \\
\hline Gastroenter & litis, unspecified & & $1(1.2)$ & \\
\hline Retention o & & & $2(2.4)$ & \\
\hline Acute prost & & & $1(1.2)$ & \\
\hline Infection du & cedure & & $1(1.2)$ & \\
\hline Septicemia, & & & $3(3.6)$ & \\
\hline Chemother & & & $1(1.2)$ & \\
\hline Cervical disk & with radiculopathy & & $1(1.2)$ & \\
\hline Disorder of & stem, unspecified & & $1(1.2)$ & \\
\hline Esophageal & th bleeding & & $2(1.2)$ & \\
\hline Measures o & tendency Actual LOS & DRG-LOS & & $p$ \\
\hline Mean & 7.55 & 4.3860 & & $<0.001$ \\
\hline Median & 5.00 & 3.6500 & & \\
\hline Percentile & 3.00 & 2.1000 & & \\
\hline & 5.00 & 3.6500 & & \\
\hline & 11.00 & 6.6000 & & \\
\hline Total & & & & \\
\hline
\end{tabular}

